\title{
Joint Slippage Model in Lattice Transmission Tower
}

\author{
Wenqiang Jiang ${ }^{\mathrm{a}}$, Zhangqi Wang ${ }^{\mathrm{b}}$ and Ziyang Zhang ${ }^{\mathrm{c}}$ \\ Department of Mechanical Engineering, North China Electric Power University, Baoding, China \\ ajwq1980@hotmail.com, bwangzq2093@163.com, chuadianzzy@126.com
}

Keywords: Lattice Transmission Tower; bolted joint slippage model; experimental verification

\begin{abstract}
The bolted connecting is prone to slip results from external load in the transmission tower as the member is thin and the pre-tightening force of bolt is small. The influence of joint slippage is usually considered in the finely analysis of transmission lines tower. In this paper, the joint slippage process was analyzed, and a new universal model was presented by considering both clearance slip process and deformation slip process. The effect of the parameters of the slip model is discussed, and the relevant parameters of the model are determined. The reliability of the new model was verified by comparing with the experimental results, which provides reliable theoretical support for the accurate analysis of lattice transmission lines tower with considering bolt joint slippage.
\end{abstract}

\section{Introduction}

Traditionally, ordinary bolt should not be used as bearing type connection in the steel structure. However, in practice the ordinary bolts are always used in shearing connection in transmission tower. For steel frame, the design codes among the entire world only give the strength design formula without special considering the influence of joint deformation. As the member is thin and the pre-tightening force of bolt is small, and furthermore there is a clearance between the bolt and the bolt hole, thus the relative slippage between the connecting parts is easy to occur. A lot of full scale tower tests shows that joint slip in lattice transmission tower are common [1-2]. For statically determinate structure, the slip of the bolt will not significantly affect the internal force of the structure. However, the joint slippage effects should be considered in the accurate analysis of transmission tower as the transmission tower is generally non-statically determinate structure.

As a result, the slippage of the bolt joint will affect the overall stiffness of the tower and the distribution of the internal force of the member. Therefore, it is necessary to study the slippage process of the bolts, in order to predict the internal force and deformation accurately during load-displacement process of the transmission lines tower[3]. In this paper the slippage process of bearing type bolted joint are analyzed in detail, and a new joint slippage model are presented, and the parameters and its effects on the slippage model are studied. The effective of the model are verified by comparing with the experimental results.

\section{Joint slippage process}

The bearing type bolted joint are commonly used in the transmission lines tower and the typical bolted joints in lattice transmission tower can be divided into single-leg bolted joint and lap-splice bolted joint as shown in the Fig. 1.

In this paper the normal clearance configuration of bolted joint was used to analysis the load-deformation process as shown in the Fig. 2. As can be seen in the figure, the $d_{0}$ is the diameter of the bolt, $D_{0}$ is the diameter of the bolt hole, $\delta_{1}$ and $\delta_{2}$ are respectively the clearance configuration which can be seen in the Fig.2(a). When a deformation is made between the bolt and bolt shrank, the bolt holes change to be $D_{1}$ and $D_{2}$, at the same time the two bolt holes change to be $d_{1}$ and $d_{2}$ at the connection parts. When the deformation of the connection pieces is ignored, the deflection of the bolt joint slip can be shown as follow 


$$
\Delta=\left(\delta_{1}+\delta_{2}\right)+\left(D_{1}+D_{2}-2 D_{0}\right)+\left(2 d_{0}-d_{1}-d_{2}\right)=\delta_{0}+u_{1}+u_{2}
$$

In which, $\delta_{0}$ is the clearance configuration, $u_{1}$ and $u_{2}$ is respectively the deflection of the wall if hole and bolt shank.

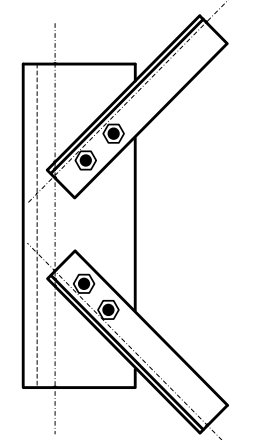

a) Single-leg bolted joint

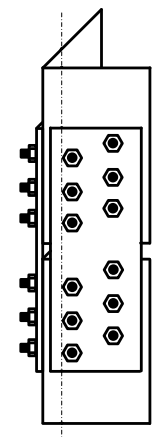

b) Lap-splice bolted joint

Fig. 1 Typical bolted joint in lattice transmission tower
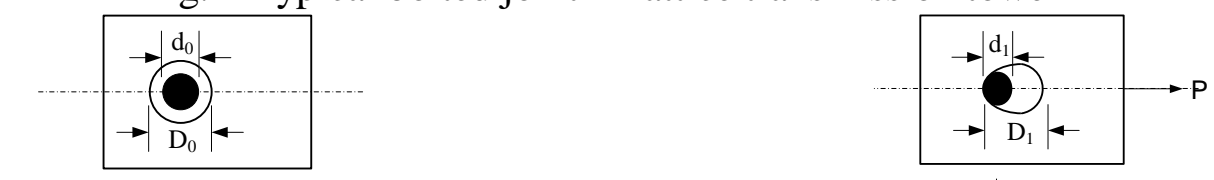

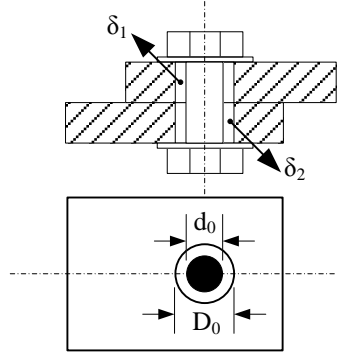

a) Before Slippage

Fig. 2 Bolted joint deformation

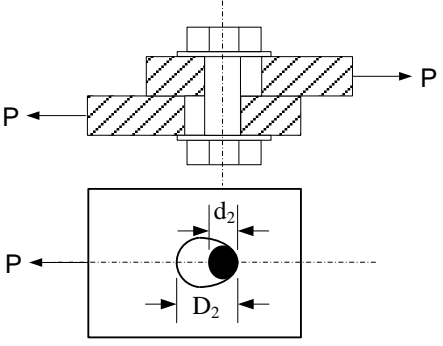

b) After Slippage

\section{The model and parameters of the joint slippage}

\subsection{The load-deformation curve of bolted joint}

As shown in Fig.3, the joint slippage process can be divvied into two parts: the clearance slippage and deformation slippage according to the properties of the load-deformation curve of bolted joint.

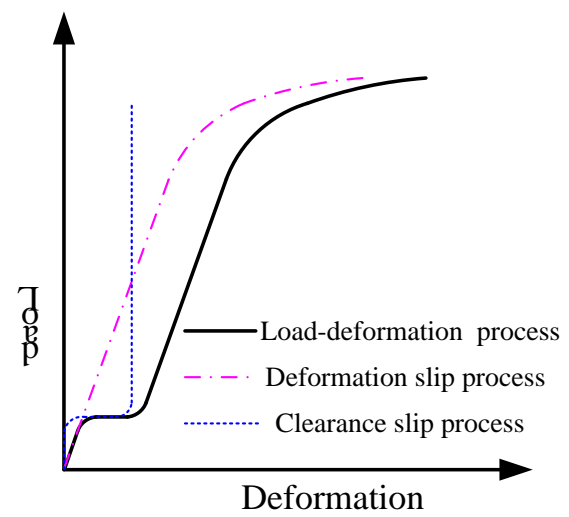

Fig.3 Load-deformation

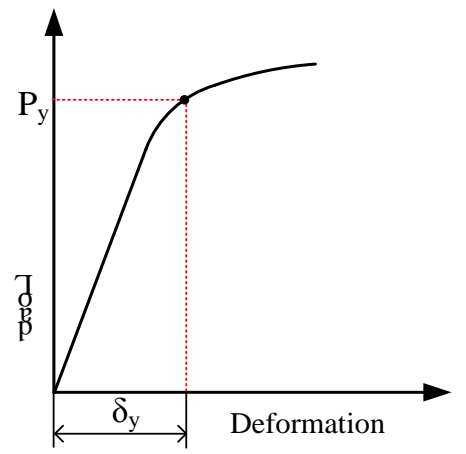

a) bolt-hole deformation curve

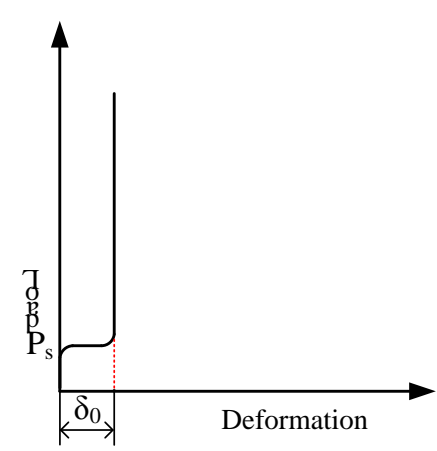

b) Slip deformation curve

Fig.4 Slippage process of bearing type bolted joint

As shown in Fig.4 (a), for the deformation slippage process, the parametric equations of the nonlinear stress-strain relationship of the material presented by Osgood and Ramberg are used here[4]. The function expression of the load-deformation process can be obtained by describing the deformation slip as below. 


$$
\Delta_{1}=\delta_{y} \frac{P}{P_{y}}+\alpha \delta_{y}\left(\frac{P}{P_{y}}\right)^{N}
$$

In which $\alpha$ and $N$ are all the shape parameters for curves.

As shown in Fig.4 (b), for the clearance slip process, the following function expression is used to descript the load deformation process[5].

$$
\Delta_{2}=\delta_{0}\left(\frac{P / P_{s}}{\left[1+\left(P / P_{s}\right)^{n}\right]^{1 / n}}\right)^{m}
$$

In which the $P_{s}$ is the slip load, $\delta_{0}$ is the slip volume for the clearance, $m$ and $n$ are all the shape parameters for curves. Through reasonable choice of the parameters $m$ and $n$, the function expression has the following features: 1 ) when $\left.P<P_{s}, \Delta_{2} \approx 0,2\right)$ when $P \geq P_{s}, \Delta_{2} \approx \delta_{0}$.

According to (2) and (3), The load-deformation curve of the bolt joint can be expressed as

$$
\Delta=\Delta_{1}+\Delta_{2}
$$

\subsection{The definition of the parameters}

The results of the Tab. 1 and Tab. 2 are the parameters of the joint slippage model that defined from the experimental results[6]. the load-deformation curves with different numbers of bolts can be acquired according to Tab. 1 and Tab. 2, and the curves are shown in the Fig. 5.

Tab. 1 Parameters for single-leg bolted joint

\begin{tabular}{ccccccccc}
\hline Number & $\delta_{0}(\mathrm{~mm})$ & $\delta_{y}(\mathrm{~mm})$ & $P_{s}(\mathrm{kN})$ & $P_{y}(\mathrm{kN})$ & $\alpha$ & $N$ & $m$ & $n$ \\
\hline 1 & 1.3 & 2.74 & 9.29 & 65.03 & & & & \\
2 & 1.3 & 1.73 & 20.14 & 91.51 & & & & \\
3 & 1.3 & 2.40 & 29.28 & 152.9 & 0.02 & 10 & 20 & 20 \\
4 & 1.3 & 1.85 & 46.95 & 168.2 & & & & \\
\hline
\end{tabular}

Tab. 2 Parameters for lap-splice bolted joint

\begin{tabular}{ccccccccc}
\hline Number & $\delta_{0}(\mathrm{~mm})$ & $\delta_{y}(\mathrm{~mm})$ & $P_{s}(\mathrm{kN})$ & $P_{y}(\mathrm{kN})$ & $\alpha$ & $N$ & $m$ & $n$ \\
\hline $2 \times 2$ & 1.3 & 2.26 & 43.30 & 216.40 & & & & \\
$2 \times 3$ & 1.3 & 2.26 & 64.95 & 324.60 & & & \\
$2 \times 4$ & 1.3 & 2.26 & 86.60 & 432.80 & & 10 & 5 & 5 \\
$2 \times 5$ & 1.3 & 2.26 & 108.25 & 514.00 & & & & \\
\hline
\end{tabular}

Single-leg bolted joint

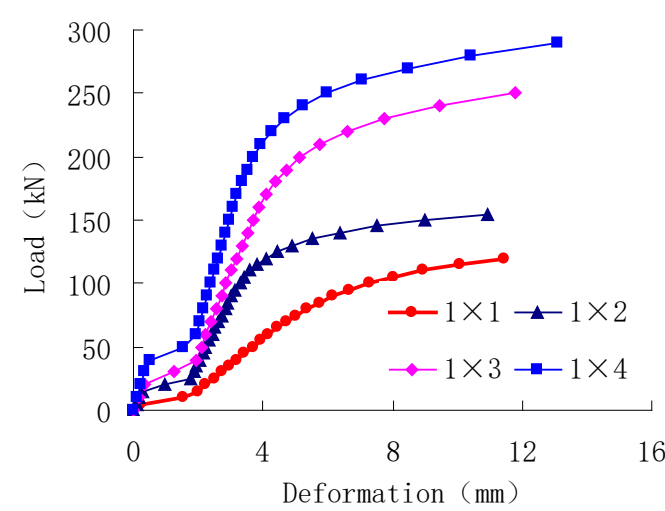

a)single-leg bolted joint lap-splice bolted joint

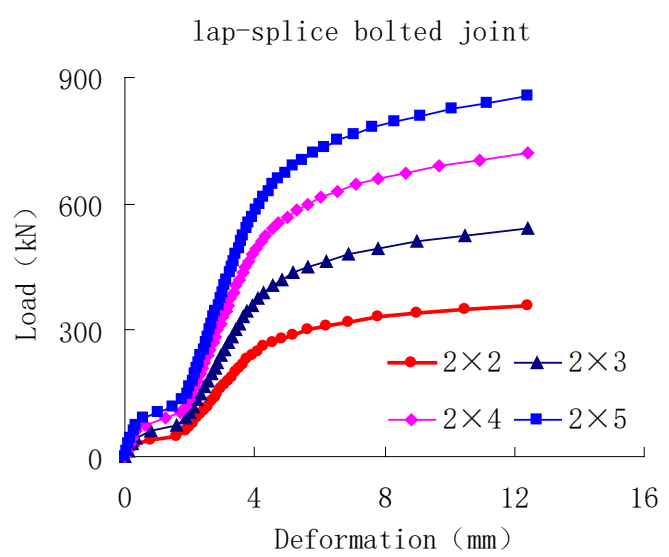

b)lap-splice bolted joint

Fig. 5 Load-deformation curve for bolted joint

\section{The experimental verification of the joint slippage model}


In order to verify the accuracy of bolted joint slippage model, the numerical model was compared with the experimental result presented by Ungkurapinan [6-7]. As can be seen in Fig.6, the load-deformation curve of single bolt and four bolts are matched very well. Therefore the presented numerical model is very effective, which can be easily used in the program of finite element analysis of lattice transmission tower as the model is smooth and derivative.

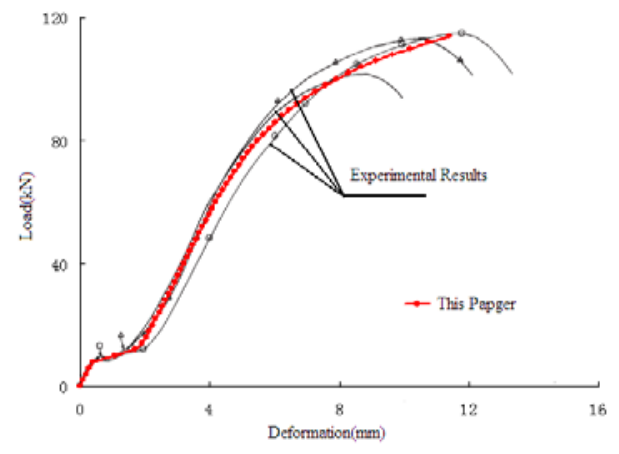

a) Single bolt connection

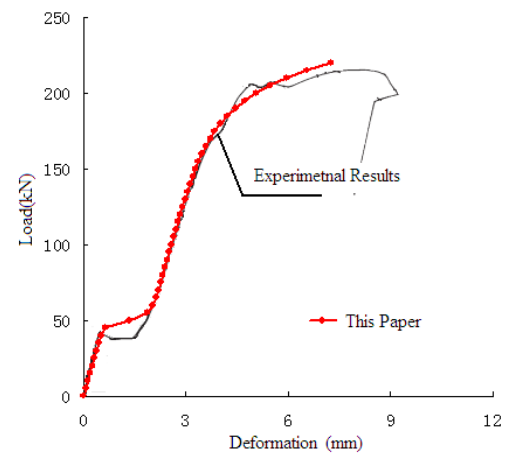

b) Four bolts connection

Fig.6 Comparison of load-deformation curves

\section{Conclusions}

In this paper, the process of the joint slippage were analyzed in detail, and a new joint slippage model was put forward according to the characteristic of the load-deformation curve. The parameters of the joint slippage model are confirmed. After comparing the joint slippage model with experiment results, the model was proofed to be good in line with the practical of the slippage process in different number of bolt.

\section{Acknowledgement}

The authors acknowledge the financial support provided by the science and technology projects of State Grid (Dynamic characteristics and ultimate behavior of lattice tower in the mining area) and the Natural Science Foundation of China (51408221).

\section{Conferences}

[1] Peterson W.O. Design of EHV steel tower transmission lines [J]. ASCE Journal of the Structural Division, 1962, 88(PO1):39-65

[2] Marjerrison M.M. Electric transmission tower design [J]. ASCE Journal of the Structural Division, 1968, 94(PO1):1-23

[3] Jiang W. Q, Wang Z. Q., G. McClure,et al., 2011, Accurate modeling of joint effects in lattice transmission towers. Engineering Structures, 33(5):1817-1827.

[4] Ramberg W., Osgood W. R. Description of stress-strain curves by three parameters [R]. Washington, 1943

[5] Kitipornchai S., Albermani F. G. A., Peyrot A. H. Effect of bolt slippage on ultimate behavior of lattice structures [J]. ASCE Journal of Structural Engineering, 1994, 120(8):2281-2287

[6] Ungkurapinan N. A study of joint slip in galvanized bolted angle connections [D]. Canada: University of Manitoba, 2000

[7] Ungkurapinan N., Chandrakeerthy S. R. D. S., Rajapakse R. K. N. D., Yue S. B. Joint slip in steel electric transmission towers [J]. Engineering Structures, 2003, 25:779-787/ 